\title{
Methodology of Management of Innovative Development of Complex Socio-Economic Systems in the Information Society
}

\author{
Yong $\mathrm{He}^{1}$, Tatiana Yu. Tsibizova ${ }^{2,3^{*}}$, Konstantin A. Neusypin ${ }^{2}$, and Maria S. Selezneva ${ }^{2}$ \\ ${ }^{1}$ Nanjing University, Nanjing, Jiangsu, China \\ ${ }^{2}$ Bauman Moscow State Technical University, 2nd Baumanskaya str., 5/1, 105005, Moscow, Russia \\ ${ }^{3}$ Russian Academy of Education, Pogodinskaya str., 8, 119121, Moscow, Russia
}

\begin{abstract}
The article presents methodological recommendations for managing the innovative development of complex socio-economic systems in the context of movement towards the information society, the formation and development of problem-oriented information and communication social spaces, the formation of specialized virtual innovation clusters, the organization of effective interaction between government bodies and local self-government, economic entities, their associations, other organizations and citizens having common interests and a common goal. The proposed methodological recommendations and model of innovative development can, with account of specific features, be effectively applied in various sectors of the national economy. Using the research results in practice will contribute to solving the problem of innovative modernization of the country, adapting authorities, organizations and citizens to the conditions of the global information society, increasing the functioning and competitiveness of complex socio-economic systems, improving quality and increasing the volume of socially significant products. An intelligent control system is proposed and a technology for managing the innovative development of complex socio-economic systems is developed.
\end{abstract}

\section{Introduction}

A prerequisite for sustainable progressive socio-economic development of the country ensuring its competitiveness is the innovative development of all sectors of the economy, individual economic entities and their associations as a way of their existence through a targeted change in their quality condition as a result of innovative activity in the face of changing environmental factors and/or changing their internal properties. For all complex socio-economic systems (SES), the main new environmental factor is the formation of a global information society. The fundamental condition for the well-being of every person, every organization and every state in the information society is knowledge gained through unhindered access to information and the ability to work with it. There is a transition from "informatization of management" to "informatization of life" [1,2]. On the basis of the

\footnotetext{
*Corresponding author: mumc@bmstu.ru
} 
global computer network Internet, problem-oriented information and communication social spaces (ICS) arise and develop, and Internet communities are formed on the basis of common goals and values. The denial of socio-economic systems to seize the opportunities provided by the information society leads them to stagnation and degradation.

The key problem of socio-economic development of Russia in modern conditions is the low competitiveness of almost all major sectors of the economy. To a large extent, this is derived by the fact that public control and administration authorities, organizations and citizens are not fully and effectively using the opportunities provided by the information society.

There are still very few works devoted to the search for opportunities that open up for citizens and organizations in the information society, the study of the phenomenon of problem-oriented information and communication social spaces, the organization of educational, economic and other activities in ICS [3, 4].

Thus, the logic of scientific research determines the relevance of developing theoretical, methodological and practical approaches to managing the innovative development of complex socio-economic systems in the information society, as well as methodological recommendations for managing the formation and development of problem-oriented information and communication social spaces $[5,6,7]$.

The working hypothesis of the study consists of the following assumptions:

- in the information society, new opportunities are opening up for improving the management of innovative development of complex socio-economic systems associated with the formation of Internet-based problem-oriented information and communication social spaces, the formation of specialized virtual innovation clusters in ICS $[8,9,10]$;

- the key system-forming elements of the ICS innovation infrastructure should be problem-oriented information and analytical Internet portals [11, 12. 13];

- the methodology for managing the innovative development of complex socioeconomic systems in the information society should involve the use of intelligent management technologies, including or based on the theory of functional systems of P. K. Anokhin.

The purpose and objectives of the study. The aim of the study is to develop theoretical, methodological and practical approaches to managing the innovative development of complex socio-economic systems in the information society, focused on the most complete realization of the opportunities that open up for citizens and organizations in connection with the development of information and communication technologies, as well as methodological recommendations on management of the formation and development of problem-oriented information and communication social spaces.

To achieve the goal of the study, it was necessary to solve the following main problems:

- to study the features of innovative development of complex socio-economic systems in the information society, including educational systems [14, 15, 16];

- to justify the need to introduce the concept of "problem-oriented information and communication space" into the scientific circulation as a form of relations existing in the process of economic and other activities by economic entities using advanced information and communication technologies, to reveal the essence of ICS, to study the conditions for its formation and development, unleash its innovative potential;

- to develop the concept of a problem-oriented information and analytical Internet portal as a key system-forming element of the ICS innovation infrastructure;

- to develop a common approach to assessing the social and economic efficiency of investing in the formation and development of ICS;

- to summarize, systematize and develop the methodological base for modeling 
innovative development of SES [17];

- to develop the concept of an intelligent SES innovation development management system in the information society;

- to develop a schematic diagram of an intellectual system for managing innovative development in the information society;

The scientific novelty of the study consists in the formation of a methodology for managing the innovative development of complex socio-economic systems in the information society, as well as in the development of a concept of an intellectual system for managing the innovative development of complex socio-economic systems in the information society and methodological recommendations for managing the formation and development of problem-oriented information and communication social spaces.

The practical relevance of the study. Developed guidelines for managing the innovative development of complex socio-economic systems in the context of Russia's movement towards the information society, the formation and development of problemoriented information and communication social spaces, the formation of specialized virtual innovation clusters in ICS, and the organization of effective interaction between government bodies and local self-government, business entities, their associations, other organizations and citizens having common other interests and goals, can, taking into account specific features, be effectively applied in various sectors of the economy. The practical use of the results of the research will contribute to solving the problem of innovative modernization of Russia, adapting government bodies, organizations and citizens to the conditions of the global information society, increasing the functioning and competitiveness of complex socio-economic systems, improving the quality and increasing the volume of socially significant products.

\section{Metods}

The leading trend in the global civilization process today is the formation of a global information society, characterized by a high level of development of information and telecommunication technologies and their intensive use by citizens, business and public authorities, the growing role of information and knowledge in society, an increase in the share of information and communication infrastructure, information products and services in gross domestic product, the formation of global information and communication area, improving the efficiency of information interaction of people, the expansion of opportunities for the most complete satisfaction of their social and personal needs for information products and services [18].

The solution of the "crucial for the country" task formulated in the preamble of the "Strategy for the Development of the Information Society in the Russian Federation" to realize the existing cultural, educational, scientific and technological potential of the country and ensure the Russian Federation a worthy place among the leaders of the global information society" in the medium term requires joint focused efforts of state authorities, business and civil society, the transition from "informatization of management" to "informatization of life" [19]. The goal of information society formation and development in the Russian Federation is to improve the quality of life of citizens, ensure the competitiveness of the country, develop the economic, socio-political, cultural and spiritual spheres of society, improve the public administration system based on the use of information and telecommunication technologies. Fundamentally new social technologies should be created as a set of methods and means of solving social problems aimed at creating the living conditions and development of society, social relations, social structure in order to meet human needs, create conditions for the realization of its abilities and interests. Information openness of state and municipal structures, facilitating citizens access 
to documents and materials directly affecting their rights and legitimate interests, providing them with complete and accurate information about the planned and actual results of activities of state authorities and local self-government bodies contribute to the development of a dialogue between the state and society, strengthening public control of power.

The global computer communication system is built on the basis of the global Internet. The Internet offers humanity a new quality of life based on the integration and active use of information resources. The mission of the Internet is to create favorable conditions for open communication of each with each other and each with all. In the global information society, progressive socio-economic development and competitiveness of individual states are ensured, first of all, by the presence of a developed "knowledge generation" environment based on a significant sector of fundamental research combined with an effective education system, a developed national innovation system, and a holistic state policy in innovation sphere and effective regulatory support of innovation.

To model the innovative development of SES, it is proposed to use systemic economic and mathematical models of the Germeier type, models of the theory of active systems and models of the theory of self-organization - synergetics [20].

As Russia moved to the market, Germeyer-type models deserve special attention today. In Germeier systems, there are no subordination relations: in market conditions, economic relations between all business entities, regardless of their organizational and legal form and form of ownership of their property, are based on the principles of equality, autonomy of will and property independence of their participants.

Where there are relationships of subordination, complex socio-economic systems and their subsystems can be considered as active systems. In active systems, one or more controlled active elements can purposefully choose their state, guided by personal interests and preferences. It is assumed that the active elements choose those states that are the best from the point of view of their interests for given control actions exerted on them by the governing body. The control actions of the governing body, in turn, depend on the state of the controlled entities. The activity of controlled subjects is also manifested in their ability to predict the behavior of the governing body - its reaction to a change in their state.

For a qualitative analysis of the processes of innovative development of SES, it is advisable to use the methods and tools of the theory of self-organization - synergetics. When conducting a qualitative analysis, the main emphasis is on determining the characteristic features of the entire process under study as a whole and on predicting its further development.

From the point of view of the theory of self-organization, ICS is a virtual platform on which some value factors related to the problem orientation of this ICS are exchanged for others. With the emergence and development of metabolic processes in ICS, a social community of social relations actors acting in the same problem space arises and develops, their value orientation is determined, and ways of their communication via the Internet are improved.

\section{Discussion and results}

Building an intellectual management system for innovative development of SES involves the implementation of a synthesis mechanism for the management goal, a dynamic expert system, methods of self-organization, decision-making and forecasting, united within the framework of functional structure of P. K. Anokhin (fig. 1).

The above-considered models of innovative development of SES, which are equations with a rigidly defined structure, under constantly changing conditions of the functioning environment and the system's own state, often become inadequate. In this regard, it is 
proposed to build predictive models, including the dominant (determining) parameters of systems, by the method of self-organization. Self-organizing models can be built in the process of functioning of the system. The adequacy of self-organizing models is determined by the minimum ensemble of selection criteria.

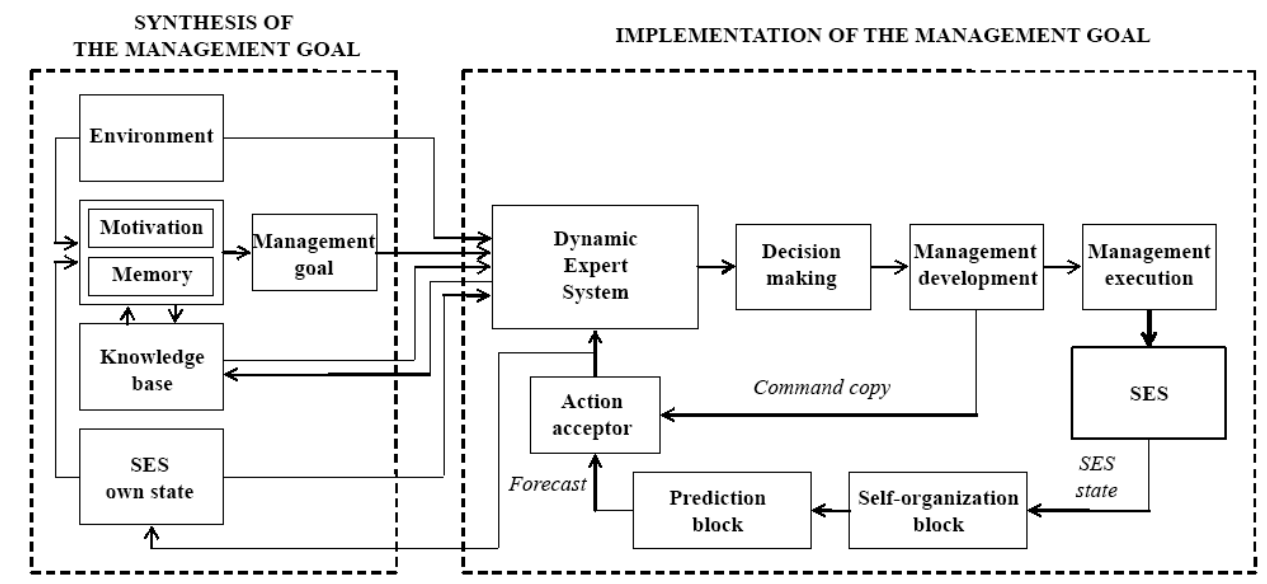

Fig. 1. Schematic diagram of the intellectual system for managing the innovative development of a complex socio-economic system

For forecasting in the intelligent innovation management system SES, for example, the following self-organizing model can be used:

$$
\varphi(x)=\sum_{i=1}^{n} a_{i} \mu_{i}\left(f_{i} x\right)
$$

where $n$ - the number of basis functions in the model, $\mu_{i}$ - basis functions from a parameterized set $F_{p}=\left\{a_{j} \mu_{j}\left(f_{j} x\right)|j=\overline{1, m}|\right\}$ (each basis function is associated with a vector of parameters $\left(a_{i}, f_{i}\right)^{T}$, where $a$-amplitude, $f$ - frequency).

The action acceptor extrapolates the studied parameters of the innovative development of the system and compares the extrapolation result with the received data. The acceptor uses self-organizing forecasting models constructed according to a method involving the combination of statistical and expert information. Information on the correspondence of the results of action and forecast is transmitted to the expert system and to the target synthesis system. If the result of the action corresponds to the forecast, the management goal is recognized as achieved, the selected management is considered correct, if not, a new expert assessment is made, a new decision is made and a new control effect is implemented. And when essentially it is impossible to achieve compliance, a new goal is synthesized.

In the conditions of the information society, the intellectual system for managing the innovative development of any complex socio-economic system can be built on the basis of the corresponding problem-oriented Internet portal (fig. 2). 


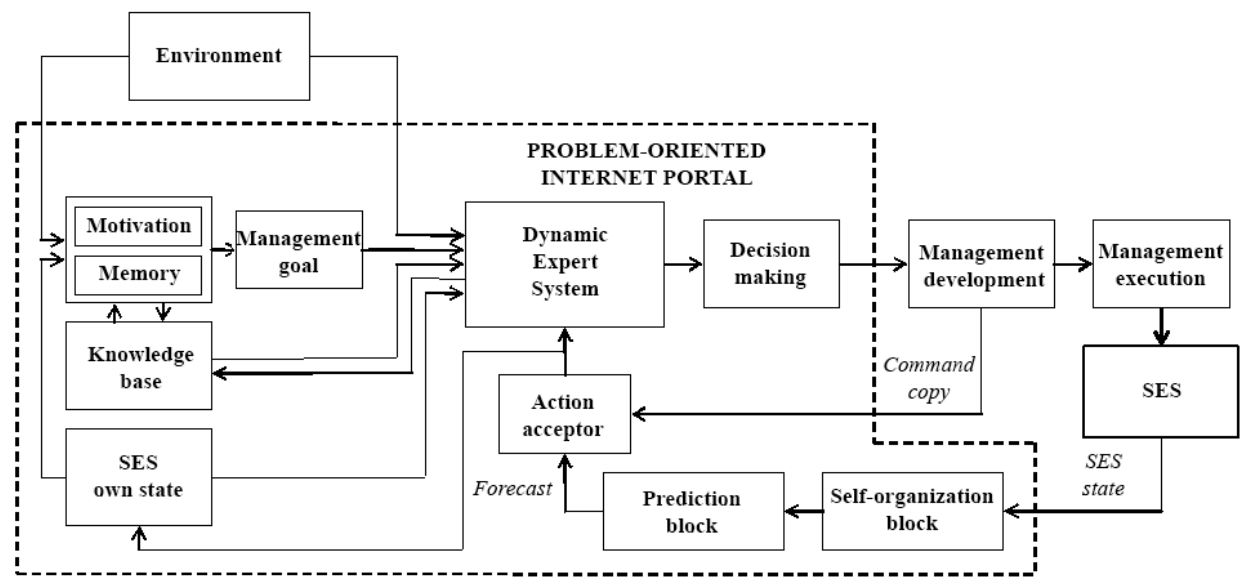

Fig. 2. The structure of the intellectual system for managing the innovative development of a complex socio-economic system based on a problem-oriented Internet portal

\section{Conclusion}

Thus, the created portal in the innovation development management system will be able to perform the following functions:

- collection, accumulation and storage of information about the state of the environment and the state of the system;

- synthesis of management goals based on active assessment of information about the state of the environment and the system's own state, as well as the prediction of these states in the presence of motivation and special knowledge;

- formation and development of a knowledge base relating to the most diverse aspects of the activity corresponding to the problem orientation of the portal;

- development of the assessment necessary for making a decision, as well as a forecast for the acceptor of action;

- decision making;

- verification by the acceptor of the action of the correspondence of the result of the action (when implementing the selected control) to the forecast.

Since the structure of the self-organizing model is not known in advance, we can take an equation with a rigidly defined structure as an a priori model, and use the self-organizing model to obtain a forecast.

\section{References}

1. N.A. Meshkov, The essence and genesis of problem-oriented information and communication social spaces, Quality. Innovation Education, No 3 (70), pp. 72-76 (2011)

2. A.A. Aleksandrov, Fang Ke, A.V. Proletarsky, K.A. Neusypin, Conception complex continuous education with innovative information technologies, Proceedings of 2nd International Conference on Education and Education Management (EEM 2012), pp. 374-378 (2012). Retrieved from www.scopus.com 
3. A.A. Aleksandrov, P.A. Kapyrin, N.A. Meshkov, K.A. Neusypin, A.E. Popovich, A.V. Proletarsky, Gamification in the advanced higher professional education: fundamentals of theory and experience of use, International Journal of Civil Engineering \& Technology (IJCIET), Vol. 9, I. 11, pp. 1800-1808 (2018). Retrieved from www.scopus.com

4. H. Etzkowitz, The Triple Helix: University-Industry-Government Innovation in action, London, Routledge, pp. 164 (2008) Retrieved from www.scopus.com

5. V.G. Brekalov, N.Yu. Terekhova, A.I. Klenin, The information model for choosing the educational process development strategy, European Social Science Journal, No. 9-3 (36), pp. 61-68 (2013)

6. M.G. Sergeeva, N.N. Bedenko, T.Yu. Tsibizova, M.S. Mohammad Anwar \& T.G. Stanchuliak, Organisational economic mechanism of managing the growth of higher education services quality, Espacios, Vol. 39 (\# 21), p. 10 (2018) Retrieved from www.scopus.com

7. S. Nicola, C. Pinto \& J. Mendonca, The role of education on the acquisition of $21 \mathrm{st}$ century soft skills by Engineering students, 3rd International Conference of the Portuguese Society for Engineering Education, CISPEE 2018 (2018). Retrieved from www.scopus.com

8. R.Sh. Akhmadieva, L.N. Ignatova, G.I. Bolkina, A.A. Soloviev, D.V. Gagloev, M.V. Korotkova, V.I. Burenina, An attitude of citizens to state control over the internet traffic, Eurasian Journal of Analytical Chemistry, 13(1), em82 (2018). Retrieved from www.scopus.com

9. M.N. Dudin, N.V. Lyasnikov, M.Y. Veselovsky, V. D. Sekerin \& V.G. Aleksakhina, The problem of forecasting and modelling of the innovative development of socialeconomic systems and structures, Life Science Journal, 11(8), pp. 549-552 (2014). Retrieved from www.scopus.com

10. L.V. Gaidarenko, O.A. Isabekova, P.A. Kapyrin, N.A. Meshkov \& A.E. Popovich, Innovation development concept of the Russian educational complex in the conditions of information society, Astra Salvensis, 6, pp. 723-734 (2018). Retrieved from www.scopus.com

11. S. Vasin, L. Gamidullaeva, G. Surovitskaya, L. Semerkova, L. Gaidarenko, Transformation of flagship universities in Russia: Assessment of development results, Proceedings of the 32nd International Business Information Management Association Conference, IBIMA 2018 - Vision 2020: Sustainable Economic Development and Application of Innovation Management from Regional expansion to Global Growth. pp. $5932-5947$ (2018). Retrieved from www.scopus.com

12. D.V. Drobyshev, K.A. Neusypin, T.Yu. Tsibizova, Distance education in the training system of highly qualified personnel, AIP Conference Proceedings 2195, 020066 (2019). https://doi.org/10.1063/1.5140166. Retrieved from www.scopus.com

13. T.P. Skorikova, S.S. Khromov \& N.V. Dneprovskaya, Distance learning in scientific and professional fields of communication (interdisciplinary approach), International Journal of Environmental and Science Education, 11(10), pp. 3467-3476 (2016). Retrieved from www.scopus.com

14. A.A. Larionova, N.A. Zaitseva, Y.F. Anoshina, L.V. Gaidarenko, V.M. Ostroukhov, The modern paradigm of transforming the vocational education system, Astra Salvensis, 6, pp. 436-448 (2018). Retrieved from www.scopus.com

15. M.G. Sergeeva, N.N. Bedenko, L.Z. Karavanova, T.Yu. Tsibizova, I.S. Samokhin \& M.S. Mohammad Anwar, «Educational Company» (technology): Peculiarities of its 
implementation in the system of professional education, Espacios, Vol. 39(2), pp. 24 (2018). Retrieved from www.scopus.com

16. S.A. Gudkova, T.S. Yakusheva, A.A. Sherstobitova, V.I. Burenina, Modeling of scientific intercultural communication of the teaching staff at smart university, Smart Innovation, Systems and Technologies 144, pp. 551-560 (2019). Retrieved from www.scopus.com

17. M.G. Sergeeva, Y.A. Chighovskaya-Nazarova, S.V. Dmitrichenkova, S.Y. Papirovskaya, V.A. Chauzova \& I.S. Andryushchenko, Effectiveness verification of the application of imitation methods of education in the training of a specialist, Espacios, 39(38), 11 (2018). Retrieved from www.scopus.com

18. S.A. Gudkova, T.S. Yakusheva, A.A. Sherstobitova, V.I. Burenina, Modeling, selection, and teaching staff training at higher school, Smart Innovation, Systems and Technologies, 144, pp. 619-629 (2019). Retrieved from www.scopus.com

19. A.S. Burlea, D.D. Burdescu, An integrative approach of E-learning: From consumer to prosumer, Smart Innovation, Systems and Technologies, 59, pp. 269-279 (2016). Retrieved from www.scopus.com

20. A.A. Gibb, Exploring the synergistic potential in entrepreneurial university development: Towards the building of a strategic framework, Annals of Innovation \& Entrepreneurship, 3, pp. 1-24 (2012). Retrieved from www.scopus.com 